\title{
DISCURSO CON MOTIVO DE LA ADOPCIÓN DE LA RESOLUCIÓN "CONSTRUIR UN MUNDO MEJOR Y MÁS PACÍFICO A TRAVÉS DEL DEPORTE Y DEL IDEAL OLÍMPICO"1
}

\author{
Thomas Bach \\ Presidente del Comité Olímpico Internacional \\ Fecha de recepción: Enero 2016 \\ Fecha de aceptación: Febrero 2016 \\ http://dx.doi.org/10.15366/citius2016.9.1.001
}

\begin{abstract}
Resumen:
El presente trabajo contiene el discurso en español de Thomas Bach, Presidente del Comité Olímpico Internacional (COI), pronunciado ante la Asamblea General de las Naciones Unidas, celebrada en Nueva York el 26 de octubre de 2015 en el que realizó una declaración con motivo de la adopción de la resolución: “Construir un mundo mejor y más pacífico a través del deporte y del Ideal Olímpico”. La publicación de este discurso pretende acercar más su contenido a toda la comunidad de hispanohablantes, difundiéndolo en su lengua materna, a fin de servir de acercamiento a las intenciones, propuestas y gestiones que desde la estructura olímpica se promueven para contribuir a la paz.
\end{abstract}

Palabras clave: Comité Olímpico Internacional, Thomas Bach, Deporte, Paz, Naciones Unidas.

Title: SPEECH ON THE OCCASION OF THE ADOPTION OF THE RESOLUTION "BUILDING A PEACEFUL AND BETTER WORLD THROUGH SPORT AND THE OLYMPIC IDEAL"

\begin{abstract}
:
This paper consists of the speech in Spanish by the President of the International Olympic Committee (IOC), Thomas Bach, delivered of the UN General Assembly in New York, on 26th October 2015. It includes a declaration regarding the resolution on "Building a peaceful and better world through sport and the Olympic Ideal". The publication of this speech seeks to bring its contents close to the Spanish speaking community, since it is delivered in its mother tongue, and to facilitate its access to the aims, proposals and dealings carried out by the Olympic institution to contribute to the cause of peace.
\end{abstract}

\footnotetext{
${ }^{1}$ Discurso pronunciado ante la Asamblea General de las Naciones Unidas, celebrada en Nueva York el 26 de octubre de 2015.
} 
Key words: The International Olympic Committee, Thomas Bach, Sport, Peace, United Nations.

Excelentísimo señor presidente de la Asamblea General de las Naciones Unidas, excelentísimos señores, distinguido público:

Es un honor para el Comité Olímpico Internacional tomar la palabra hoy ante la Asamblea General de las Naciones Unidas.

El COI quiere dar las gracias al Gobierno de Brasil y a sus representantes ante las Naciones Unidas por haber presentado esta resolución en la Asamblea General como preludio de los Juegos Olímpicos y Paralímpicos que se celebrarán el año que viene en Río de Janeiro.

También deseamos transmitir nuestro más sincero agradecimiento al Grupo de Amigos del Deporte y a todos los Estados que han copatrocinado esta resolución, así como al asesor especial del Secretario General de las Naciones Unidas sobre el Deporte para el Desarrollo y la Paz por su apoyo en favor de la inclusión del deporte en los trabajos de las Naciones Unidas.

Tanto las Naciones Unidas como el COI se basan en los valores compartidos de tolerancia, solidaridad y paz. Como describió perfectamente el secretario general de la ONU, Ban Ki-Moon: "los Principios Olímpicos son los Principios de las Naciones Unidas".

El COI encomia una vez más a la Asamblea General por haber reconocido, en su Agenda 2030 para el Desarrollo Sostenible, que el deporte es un facilitador importante para fomentar la paz y el entendimiento.

Como ya dije en la última Cumbre de las Naciones Unidas para el Desarrollo Sostenible, quiero reiterar que las Naciones Unidas y todos sus Estados miembros pueden contar con el apoyo inquebrantable del COI para alcanzar nuestra meta común de un desarrollo pacífico de la humanidad.

Con nuestra Agenda Olímpica 2020, estamos plenamente en consonancia con la Agenda 2030 de las Naciones Unidas. En particular, en lo relativo al objetivo de desarrollo sostenible 16 , que se refiere a la construcción de instituciones eficaces e inclusivas que rindan cuentas.

El COI, gracias a la Agenda Olímpica 2020, actúa de conformidad con las normas más estrictas en materia de buena gobernanza y transparencia. A este 
respecto, estamos pidiendo a otras grandes organizaciones deportivas que lleven a cabo rápidamente las reformas necesarias para restaurar su reputación.

La Tregua Olímpica refleja nuestros valores compartidos de tolerancia, solidaridad y paz. El deporte está en una posición única para poner en práctica el espíritu de la Tregua Olímpica. El deporte es el único ámbito de la existencia humana que se rige por una ley universal. Independientemente de dónde practiquemos deporte, las normas serán las mismas para todos. Se basan en los valores que compartimos. El deporte siempre se centra en tender puentes, nunca en levantar obstáculos.

Pero solo podemos tender puentes si se respeta nuestra autonomía y nuestra neutralidad. En el interés mutuo del deporte y la política, les aliento a que sigan protegiendo y reforzando la autonomía del deporte, como hicieron el pasado mes de octubre cuando adoptaron una resolución de la ONU en la que se reconoce la autonomía del deporte.

En el deporte olímpico todo el mundo es igual, independientemente de su raza, sexo, condición social, contexto cultural, fe o religión. Este Principio Fundamental de no discriminación permite que el deporte promueva la paz y el entendimiento entre todos los pueblos.

Los Juegos Olímpicos son la culminación de esta visión. Durante los Juegos, los valores de tolerancia, solidaridad y paz cobran vida. La comunidad internacional se reúne para competir pacíficamente.

En la Villa Olímpica, se pueden ver ejemplos de tolerancia y solidaridad en su estado más puro. Allí conviven armoniosamente y sin ningún tipo de discriminación atletas de los 206 Comités Olímpicos Nacionales. Este es el verdadero espíritu de "unidad olímpica en la diversidad": atletas de todos los rincones del mundo conviviendo bajo un mismo techo.

En la Villa Olímpica, que es literalmente una aldea global, los atletas aprenden a conocerse y a comprenderse compartiendo experiencias, emociones y comidas. También comparten su respeto por la excelencia, la victoria y la derrota. Así, los atletas olímpicos son un ejemplo de que es posible competir y, al mismo tiempo, vivir juntos pacíficamente.

En este espíritu olímpico de paz y solidaridad, el COI y la ACNUR $^{2}$ asisten a refugiados en todo el mundo para llevarles actividad, esperanza y confianza en sí mismos a través del deporte.

${ }^{2}$ ACNUR: Agencia de la ONU para los Refugiados. http://www.acnur.org/t3/ 
En 2014, el secretario general de las Naciones Unidas nombró a nuestro Presidente de Honor Jacques Rogge enviado especial para los Jóvenes Refugiados y el Deporte. El COI se alegra de poder respaldar económicamente estas actividades y ha creado un fondo adicional de 2 millones de dólares USA para llevar esperanza a los refugiados a través del deporte.

Al mismo tiempo, ayudamos a los atletas refugiados de alto nivel a proseguir su carrera deportiva. Les ayudamos a hacer realidad su sueño de excelencia deportiva, a pesar de haber tenido que huir de la violencia y el hambre. Me gustaría solicitar la colaboración de todos los Estados miembros de la ONU para identificar a estos grandes atletas prometedores.

En principio, estos atletas no tendrían ninguna posibilidad de participar en los Juegos Olímpicos aunque se hubieran clasificado, ya que, por su condición de refugiados, no tienen ningún país de origen ni Comité Olímpico Nacional al que representar.

Hoy, tengo el placer de anunciar a la Asamblea General de la ONU que el Comité Olímpico Internacional invitará a los atletas refugiados mejor clasificados a participar en los Juegos Olímpicos de Río 2016. Como no pertenecen a ninguna delegación nacional y no tienen ninguna bandera bajo la que desfilar ni ningún Himno Olímpico, participarán bajo la Bandera Olímpica y con el Himno Olímpico. Se alojarán en la Villa Olímpica junto con los otros 11.000 atletas de los 206 Comités Olímpicos Nacionales (CONs). Será un símbolo de esperanza para todos los refugiados del mundo y permitirá dar a conocer mejor la magnitud de esta crisis.

Otro ejemplo reciente de cómo el deporte puede promover la paz y la inclusión fue el reconocimiento del CON de Sudán del Sur por parte del COI. Con este reconocimiento, queríamos enviar un mensaje de esperanza a una joven nación y a su pueblo, una señal de esperanza porque el deporte siempre tiende puentes entre las personas y culturas. El presidente del recientemente creado CON de Sudán del Sur dio las gracias a la Sesión del COI con estas palabras: "Ahora, armaremos a nuestros jóvenes con deporte, no con pistolas".

Este es el espíritu de la Tregua Olímpica que defenderán con el respaldo a la resolución de hoy.

Los Juegos Olímpicos son la ocasión en la que la comunidad internacional se reúne para celebrar nuestra humanidad común. No me cabe ninguna duda de que los próximos Juegos Olímpicos y Paralímpicos de Río 2016 serán el escenario ideal para mostrar lo mejor del espíritu de la humanidad. 
Podemos esperar unos Juegos Olímpicos ejemplares. Quiero reiterar la sincera invitación que extendió el Comité Organizador, hábilmente dirigido por nuestro amigo y colega Carlos Nuzman, a la comunidad internacional para que se reúna en Río de Janeiro en 2016. Brasil y los brasileños brindarán una calurosa bienvenida al mundo y nos sorprenderán con su alegría de vivir y su pasión por el deporte. A través de los Juegos Olímpicos, el pueblo brasileño recordará al mundo su mezcla única de pasión y eficiencia.

La historia hablará de un Río de Janeiro antes de los Juegos Olímpicos y de otro Río de Janeiro, mucho mejor, después de los Juegos. La ciudad está preparando un legado olímpico a través de medidas muy concretas. Las indispensables mejoras del sistema de transporte público y de los programas educativos para todos beneficiarán a las generaciones futuras. Los Juegos Olímpicos de Río ya son un símbolo, gracias a los esfuerzos del país por construir un mundo mejor para todos sus ciudadanos.

Los valores de tolerancia, solidaridad y paz son un elemento central del legado de Río de Janeiro para todos los brasileños. Pondrán de manifiesto la importancia clave del deporte para alcanzar la paz, la inclusión social y la tolerancia, y para luchar contra la discriminación racial, étnica o de género. Deseo alabar los esfuerzos de Brasil y del Movimiento Paralímpico por promover los derechos y la inclusión de las personas con discapacidad en los Juegos Paralímpicos y más allá. Es otro ejemplo más de cómo el deporte puede impulsar el cambio social. Otro es la cooperación entre el COI y ONU-Mujeres. Nuestra iniciativa conjunta está destinada a chicas de entre 12 y 14 años de los colegios del estado de Río de Janeiro. A través de una serie de programas deportivos, les proporcionamos las herramientas que les permitan llegar a ser futuras dirigentes.

La misión del COI es poner el deporte al servicio de la humanidad. Somos conscientes de que solo lo conseguiremos si nos asociamos con otros. Por eso, hoy reafirmamos nuestro firme compromiso de colaborar con las Naciones Unidas y sus Estados miembros para hacer de nuestros objetivos compartidos una realidad.

La Tregua Olímpica puede darnos a todos la esperanza de un mundo mejor. Con su apoyo hoy a la resolución sobre la Tregua Olímpica, espero que los Juegos Olímpicos de Río 2016 se conviertan en un sinónimo de los esfuerzos de la comunidad internacional por construir un mundo mejor y más pacífico para todos a través del deporte. 